\title{
"TRADUÇÃO" DA ESCOLA UNITÁRIA DE GRAMSCI PELA PEDAGOGIA HISTÓRICO-CRÍTICA DE SAVIANI
}

\author{
THE "TRANSLATION" OF GRAMSCI'S UNITARY SCHOOL BY THE \\ HISTORICAL-CRITICAL PEDAGOGY OF SAVIANI
}

\section{LA "TRADUCCIÓN" DE LA ESCUELA UNITARIA DE GRAMSCI POR LA PEDAGOGÍA HISTÓRICO-CRÍTICA DE SAVIANI}

Marcos Francisco Martins ${ }^{1}$

\section{RESUMO}

Este artigo é resultante de pesquisa bibliográfica sobre as formulações de Gramsci e de Saviani em relação à escola. São empregados textos gramscianos do período pré-carcerário e carcerário, para demonstrar que a preocupação do sardo com a "tradução" nasceu na juventude, amadurecendo posteriormente. Entre as obras de Saviani, são focadas as que marcaram o nascimento da pedagogia histórico-crítica. Defende-se a ideia de que a pedagogia originariamente produzida por Saviani é tradução da escola unitária de Gramsci. A exposição é dividida em três partes: na primeira, consta a leitura do conceito de tradução e tradutibilidade em Gramsci; na segunda, há a caracterização da escola unitária; na parte final, a concepção gramaciana de escola é aproximada da de Saviani, para demonstrar que pode ser interpretada como tradução daquela.

PALAVRAS-CHAVE: Gramsci. Dermeval Saviani. Escola unitária. Pedagogia histórico-crítica.

\section{ABSTRACT}

This article is the result of a bibliographical research on the formulations of Gramsci and Saviani on school. Gramscian texts from the precarceral and prison periods are used to demonstrate that the Sardinian's concern with "translation" was born in his youth, later maturing. Among Saviani's works are those that marked the birth of historical-critical pedagogy. It defends the idea that this pedagogy, originally produced by Saviani, is a translation of Gramsci's unitary school. The exposition is divided into three parts: in the first one, the reading of the concept of translation and translatability in Gramsci; in the second, there is the characterization of the unitary school; in the final part, Gramsci's conception of the school is approximated by Saviani, to demonstrate that this can be interpreted as a translation of that.

KEYWORDS: Gramsci. Dermeval Saviani. Unitary school. Historical-critical pedagogy. Translation.

\section{RESUMEN}

Este artículo es resultado de la investigación bibliográfica sobre las formulaciones de Gramsci y Saviani en relación a la escuela. Se emplean textos gramscianos del período precarcelario y carcelario, para demostrar que la preocupación del sardo con la "traducción" nació en la juventud, madurando posteriormente. Entre las obras de Saviani, se enfocan las que marcaron el nacimiento de la pedagogía histórico-crítica. Se defiende la idea de que la pedagogía originariamente producida por Saviani es traducción de la escuela unitaria de Gramsci. La exposición se divide en tres partes: en la primera, consta la lectura del concepto de traducción y traducibilidad en Gramsci; en la segunda, hay la caracterización de la escuela unitaria; en la parte final, la concepción gramaciana de escuela es aproximada a la de Saviani, para demostrar que puede ser interpretada como traducción de aquella.

PALABRAS CLAVE: Gramsci. Dermeval Saviani. Escuela unitaria. Pedagogía histórico-crítica. Traducción.

\footnotetext{
${ }^{1}$ Doutor em Educação - Universidade Estadual de Campinas (UNICAMP) - Campinas, SP - Brasil. Docente do Departamento de Ciências Humanas e Educação (DCHE) - Universidade Federal de São Carlos (UFSCar) - São Carlos, SP - Brasil. E-mail: marcosfranciscomartins@gmail.com

Submetido em: 18/07/2017 - Acesso em: 08/12/2017
}

$\begin{array}{llllll}\text { (C) ETD- Educação Temática Digital } & \text { Campinas, SP } & \text { v.20 } & \text { n.4 } & \text { p.997-1017 } & \text { out./dez. } 2017\end{array}$




\section{INTRODUÇÃO}

É controverso o lugar da pedagogia histórico-crítica, formulação original de Saviani, no interior do marxismo. Assim, adotou-se o conceito de tradução de Gramsci para avaliar sua origem e desenvolvimento, e verificar qual a relação que mantém com o legado do sardo.

Embora haja menção a uma pergunta oral feita a Saviani durante evento recente (2017), a pesquisa cujos resultados são aqui apresentados é essencialmente bibliográfica. De Gramsci são empregados textos pré-carcerários e carcerários, para demonstrar que a tradução foi preocupação constante nas formulações teóricas e na prática política do sardo. De Saviani são utilizadas bibliografias que revelam que, na produção da pedagogia históricocrítica, ele se referenciou fortemente em Gramsci, a partir de uma leitura leninista.

A tese defendida é que Estado, hegemonia, bloco histórico, concepções de mundo, reforma moral e intelectual, ideologia e intelectuais, são conceitos "traduzidos" por Saviani ao formular a referida pedagogia, sendo a escola unitária o principal referente, com destaque à cartese, que é traduzida de Gramsci para indicar o ponto culminante do processo educativo.

Na primeira parte deste texto há uma leitura do conceito de tradutibilidade e tradução em Gramsci para, depois de apresentar aspectos da escola unitária de Gramsci (segunda parte), empregá-los na análise da pedagogia histórico-crítica (terceira parte). Argumenta-se favorável à tese de que a pedagogia de Saviani é uma tradução da escola unitária de Gramsci.

Assim construído, este artigo pode interessar a amplo público da área da educação e da pesquisa em educação, nomeadamente aos que estudam ou têm orientação em Gramsci e/ou Saviani, bem como nas formulações escolares que produziram.

\section{GRAMSCI, TRADUTIBILIDADE E TRADUÇÃO}

Tradutibilidade e tradução são conceitos ainda pouco discutidos por estudiosos de Gramsci, embora colaborem com a interpretação de seu legado e possam orientar a práxis com vistas a construir uma nova civilização. Tradutibilidade diz respeito à "possibilidade teórica de traduzir algo [enquanto que tradução refere-se à] atividade prática de traduzir" (BOOTHMAN, 2017, p. 782).

Gramsci, interessado pelas línguas, estudou Filologia Moderna na Faculdade de Letras de Turim, onde se identificou com o glotologista Matteo Bartoli (FIORI, 1979, p. 94 e 104). Em carta à cunhada Tatiana (19/03/1927), manifestou interesse em "fazer algo für ewig me ocupar intensa e sistematicamente de um estudo de lingüística comparada"

$\begin{array}{llllll}\text { (C) ETD- Educação Temática Digital } & \text { Campinas, SP } & \text { v.20 } & \text { n.4 } & \text { p.997-1017 } & \text { out./dez. } 2017\end{array}$


(GRAMSCl, 2005a, p. 128). Porém, a abordagem gramsciana da tradução não a limitou a problema restrito ao universo linguístico, pois a reporta à dimensão ético-política da luta pela superação do capitalismo, tanto quando trata da tradutibilidade das línguas nacionais em outras línguas, como quando analisa as possibilidades de tradução de uma cultura a outra ou mesmo entre paradigmas científicos e filosóficos (BOOTHMAN, 2017).

As origens da tradutibilidade nas formulações de Gramsci residem nas situações que viveu e que envolveram a linguagem ${ }^{1}$, sempre articulada, subalterna e organicamente, ao desafio práxico revolucionário de transição ao socialismo, em uma "dimensão popularnacional" (SCHIRRÚ, 2017) na Itália e nas sociedades de tipo ocidental. Isso fez da política o "tema central" desenvolvido nos Cadernos (BIANCHI, 2008, p. 17). "É a política que forma o núcleo central do pensamento de Gramsci [mas] ele não se tornou um 'politicista'" (COUTINHO, 1999, p. 90), ou seja, "não coloca a subjetividade acima da objetividade [...] não põe a política acima da economia" (Idem, Ibidem, p. 95 - itálicos do autor), não separa estrutura-superestrutura ${ }^{2}$, mas as interpreta de modo orgânico, a partir do cabedal de conceitos que formulou e que se tornou guia para a práxis revolucionária em sociedade ocidentais, ao mesmo tempo em que possibilitou a Gramsci combater teoricamente "em duas frentes: contra as tendências auto-intituladas ortodoxas, que fundam o marxismo sobre o materialismo vulgar (como é o caso de Bukharin) e contra concepções idealistas ou especulativas (Croce)" (COUTINHO e KONDER, 1995, p. 4). Nesse percurso, ao reconhecer a luta de classe como estruturante da totalidade concreta (MARTINS, 2013), ela se torna fundante da tradução; logo, "o ato de traduzir nunca é neutro" (BOOTHMAN, 2017, p. 780).

Ao tratar da tradutibilidade, Gramsci partiu da fala de Lênin ao IV Congresso da Internacional Comunista (1922), que discutiu as resoluções do Congresso anterior e as possibilidades da revolução mundial, pois a Russa não teve êxito de ser traduzida para outros contextos (LÊNIN, 1980, p. 627): "Vilitch escreveu ou disse: não soubemos 'traduzir' nas línguas européias a nossa língua" (GRAMSCI, Cad. 11, § 46 - 1999, p. 185). A referência evidencia preocupação com os fracassos revolucionários no ocidente, como o Biênio Vermelho italiano (1919-1920). Como "a Revolução Russa e a sua tradução para a experiência dos Conselhos de Fábrica em Turim" (LACORTE, 2014, p. 61) foi derrotada, surgiu em Gramsci a dúvida: como traduzi-la a outros contextos? ${ }^{3}$

A tradução se reporta ao "reconhecimento da complexidade do fenômeno das crises orgânicas" (STACCONE, 1995, p. 110), o que obriga "Gramsci a buscar caminhos novos e originais para a 'solução revolucionária' válida para o mundo ocidental, que tem como pressuposto partir do reconhecimento das situações nacionais" (Idem, Ibidem). Assim, ela desautoriza leituras de Gramsci que tomam a linguagem como estruturante, como a de Lo Piparo: "a matriz primitiva da sua filosofia não deveria ser buscada em Marx, em Lênin ou em qualquer outro marxista, mas na ciência da linguagem." (LO PIPARO, 2008, s/p.) 
Gramsci não pode ser reduzido a linguista, mas contribuiu com esse campo. Ao abordar a tradução, afastou-se da visão técnica, neutra: transposição fidedigna de um texto a outra língua, com vistas a ser o mais fiel ao original. Tradutibilidade em Gramsci não objetiva a reprodução ipsis litteris, até porque, à tradução "qualificada não basta traduzir literalmente" (GRAMSCl, carta a Giulia de 05/09/1932 - 2005b, p. 237). Distanciou-se até da extensão imediata da tradução à política: tradução de uma teoria ou prática de um contexto ao outro, ou ainda da teoria à prática ou vice-versa, sem a mediação da análise concreta das situações da tradução. Por isso criticou traduções abstratas do marxismo, como a do Manual de Sociologia de Bukharin, pois desconsiderava diferenças de desenvolvimento entre oriente e ocidente para popularizar cânones do marxismo com leitura nada dialética (economicismo vulgar). Como ortodoxo ao marxismo originário, Gramsci admitiu como critério de validade da tradução "as classes e as forças sociais populares da sociedade de destino [...] são elas que decidem sobre a qualidade de uma tradução" (BOOTHMAN, 2017, p. 780).

Dado o "'fundo' essencial" (GRAMSCl, Cad. 11, § 48 - 1999, p. 187) de experiências ético-políticas e culturais em alguns contextos, há condições de elas serem reproduzidas em outras formações sociais, em "linguagens de culturas nacionais" (Idem, Ibidem, p. 186), desde que adequadamente traduzidas, o que possível apenas na "filosofia da práxis [pois nela] a 'tradução' é orgânica e profunda, enquanto de outros pontos de vista trata-se frequentemente de um mero jogo de esquematismos genéricos" (Idem, Ibidem, p. 185). Assim, Gramsci entendeu a tradução da filosofia clássica alemã pela Revolução Francesa, uma vez que aquela, que "contém a revolução em forma de pensamento, na França explicitou-se como realidade efetiva" (Idem, Ibidem, p. 188). Citando Carducci: "Kant decapitou Deus; Robespierre, o rei" (Idem, Ibidem, p. 188), pois há "princípios teóricos [que permitem] tradução recíproca, um está implícito no outro." (GRAMSCl, Cad. 11, § 65 - 1999, p. 209)

Para Gramsci, traduzir "Não foi simples operação técnica de passagem de uma língua a outra, mas sim uma verdadeira tradução cultural na qual o texto, lido em diferente contexto, adquiria novos significados" (BIANCHI, 2017b, p. 29). Logo, "Traduzir não significa repetir, mas recriar" (MENESES, 2017, s/p.); é esforço de transpor uma práxis, particularmente a do materialismo histórico-dialético, de um a outro contexto, de uma formação social (oriente) a outra (ocidente), com vistas ao socialismo. Daí o imperativo de apurada análise histórica dos contextos como critério de intervenção, o que exige conhecimento da práxis originária e do contexto de transposição, bem como disposição política e competência técnica para atualizar a teoria e a prática, para efetivar o objetivo almejado. "Não existe em Gramsci, como também no marxismo originário e no marxismoleninismo, revolução social sem a análise concreta da situação concreta" (MARTINS, 2008a, p. 254). Isso "constitui a alma viva do marxismo" (LÊNIN apud BIANCHI, 2017a, p. 7), o mais

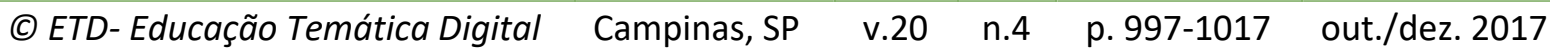


elementar de seu método: "análises concretas [sem] frases vazias comparações e forçadas" (LÊNIN, 1972, p. 399 - itálicos do autor).

A partir dessa premissa, Gramsci entendeu que tradutibilidade implica reconhecer "semelhanças" (BOOTHMAN, 2017) nas estruturas sociais para se traduzir um texto a outro contexto (GRAMSCl, Cad. 11, § 47 - 1999, p. 185), a práxis de uma formação social a outra, pois "duas estruturas fundamentalmente similares têm superestruturas 'equivalentes' e reciprocamente traduzíveis, qualquer que seja a sua linguagem particular nacional" (GRAMSCI, Cad. 11, § 49 - 1999, p. 190). Em outros termos, "a filosofia, a economia e a política [têm] 'tradutibilidade' mútua, garantida pelo fato de que todas são atividades de linguagem e, portanto, podem ser traduzidas em uma na outra pela linguagem" (SCHIRRÚ, 2017, p. 43). Reconhece-se que "problemas decorrentes do tipo de organização e estrutura social, mesmo que em nações diversas ou em comunidades diferentes, podem se reproduzir" (SILVEIRA JÚNIOR, 2015, p. 68), mas atualizando o essencial da práxis originária para "adequá-la às condições concretas" (GRAMSCI, O Programa de L'Ordine Nuovo L'Ordine Nuovo, 1924 - 2004b, p. 248), "não de modo abstrato, e sim com base na experiência efetiva" (GRAMSCI, Cad. 24, § 3 - 2000a, p. 206). Considera-se a "diversidade determinada pela tradição particular de cada cultura nacional e de cada sistema filosófico" (GRAMSCl, Cad. 11, § 47 - 1999, p. 185), para "traduzir um mundo cultural na linguagem de outro, encontrar as semelhanças mesmo onde elas parecem não existir, e saber descobrir as diferenças mesmo onde parecem existir apenas semelhanças" (GRAMSCl, Cad. 7, § 81 2000a, p. 240).

Foi isso que Marx e Engels fizeram, bem como Lênin. Os primeiros traduziram as necessidades do proletariado do século XIX na "linguagem" do que era o desenvolvimento maior do espírito à época: a filosofia clássica alemã, a economia política inglesa e o socialismo francês (LÊNIN, 1985). Mas superaram-no com a síntese teórica que formularam e com novas práticas políticas. Lênin traduziu o marxismo originário a uma sociedade tipicamente oriental, embora Marx e Engels sugeriram que a revolução ocorreria em contexto com alto desenvolvimento das forças produtivas, como a Inglaterra, e não na Rússia, agrária e semifeudal. Nisso se apegavam marxistas para sustentar posições reformistas, abstratas e mecanicistas: desenvolver o capitalismo, pois dele inevitavelmente viria o socialismo (GRAMSCl, Avanti! - A revolução contra O capital, 24/12/17 - 2004a, p. 126). Mas, sob a liderança de Lênin, os bolcheviques traduziram o marxismo e "aceleraram o futuro" (GRAMSCI, - A revolução contra O capital, 24/12/17 - 2004a, p. 128-129 e GRAMSCI, La Città Futura -, 11/02/1917 - 2004a, p. 94-95), contra o "positivismo filosófico, construção mecânica de fatalismo" (GRAMSCI, La Città Futura -, 11/02/1917 - 2004a, p. 9293). 
Gramsci, além de exercitar traduções "dos conceitos de Croce para a linguagem da filosofia da práxis" (BOOTHMAN, 2017, p. 781), de Maquiavel e outros, tentou traduzir a Revolução Russa para a Itália ${ }^{4}$, espelhando os Conselhos de Fábrica nos sovietes. A tentativa fracassada dos Conselhos o levou a refletir sobre as condições da revolução no ocidente, o que fez no cárcere. Com isso, atualizou do marxismo ao século $X X^{5}$, seja teoricamente, com a "filosofia da práxis", seja com inovações na práxis. Ao romper com a dicotomia teoria e prática, estrutura e superestrutura, ser e pensar (GRAMSCI, Cad. 11, § 37 - 1999, p. 175), traduziu a seu modo o núcleo duro do materialismo histórico-dialético nos termos da filosofia da práxis ${ }^{6}$. Nesse movimento, destacou o peso da superestrutura na determinação da vida social e nesta sobressaiu a problemática da educação.

No debate sobre tradutibilidade, Gramsci "ancora a linguagem na realidade social" (BOOTHMAN, 2017, p. 784) e, assim, "antecipa em mais de três décadas o que emergirá como disciplina da sociolinguístiva e a assim chamada 'viragem cultural' entre os tradutólogos na década de 1980" (Idem, Ibidem, p. 782). Ele articulou dialeticamente política e o "linguístico-simbólico-cultural, entrelaçadas como teoria da hegemonia (LACORTE, 2014, p. 64). De modo que a tradução ganha novo significado, atualiza concepções de mundo, reorienta ações e contém: a) conteúdo: a filosofia como concepção de mundo; b) forma variável: depende da análise concreta da situação concreta; c) sujeito: os intelectuais (SILVEIRA JÚNIOR, 2015, p. 69 e 77); d) objetivo: produzir uma nova civilização, superar o capitalismo como modo de produção da vida social, isto é, construir o socialismo.

Tem-se tentado traduções do legado teórico-prático do sardo no Brasil, como a escola unitária, traduzida por Saviani à realidade nacional nos termos da pedagogia histórico-crítica.

\section{A ESCOLA UNITÁRIA DE GRAMSCI}

Gramsci é apropriado por diversas correntes de pensamento, até por liberais (AGGIO, 2015 e BOBBIO, 1982), que costumeiramente defendem a autonomia da sociedade civil, algo distante da concepção dialética do sardo sobre a relação entre estrutura e superestrutura, expressa, particularmente, no conceito de bloco histórico (MARTINS, 2008b). Mas, Gramsci é um marxista e marcas dessa identidade se expressa, por exemplo, nas traduções que fez do marxismo originário e de Lênin em relação à educação e à escola (no sentido amplo em que a compreendia - JESUS, 2005, p. 87), as quais guardam:

a) dois fundamentos: entender a educação como imanente ao devir do processo histórico de produção do ser social e assumir o trabalho como princípio educativo; b) um compromisso ético-político: assumir a luta de classes como elemento articulador do processo educativo, com vistas a superar a sociabilidade capitalista que desumaniza o homem (MARTINS, 2016, p. 190). 
É impossível compreender educação e escola em Gramsci sem articulá-las aos conceitos que formulou para compreender as sociedades ocidentais como totalidade concreta, com vistas à construção do socialismo. Entre as teses centrais de sua concepção educativa está a que afirma que educação é política e que política tem dimensão educativa, relação ainda mais acentuada nas sociedades ocidentais. De fato, "toda geração educa a nova geração, forma-a; e a educação é a luta contra os instintos ligados às funções biológicas elementares, uma luta contra a natureza, a fim de dominá-la e de criar o homem 'atual' à sua época" (GRAMSCl, Cad. 1, § 123 - 2000a, p. 62). A educação não é apartada das relações de poder; delas emerge e, retroalimentando-as, forma um tipo de homem e de civilização. Tal processo é mediado pela força do aparato da sociedade política e pela direção intelectual e moral da sociedade civil. Assim, "Toda a relação de 'hegemonia' é necessariamente uma relação pedagógica" (GRAMSCI, Cad. 10 - Parte II, § 44 - 1999, p. 399).

Ao considerar as especificidades da dinâmica das sociedades ocidentais, Gramsci, sobretudo no cárcere, atualizou a estratégia revolucionária, não a reduzindo à tomada da sociedade política, o Estado no estrito senso do termo, e nem apenas ao controle do território da produção material, pelas guerras de movimento. A superação do capitalismo exige também guerras de posição, embates no campo cultural, ético, filosófico, religioso ..., para produzir reforma moral e intelectual. Se educação é mecanismo de reprodução da hegemonia que a base material construiu historicamente, a escola pode se tornar espaço de luta pelo socialismo ao assumir outro papel no complexo superestrutural (BETTI, 1981, p. 170).

Essa é a função da escola unitária, que Gramsci forjou a partir de críticas às escolas da época: a) a burguesa: interesseira, pragmática (profissionalização precoce) e garantidora de condições de exploração dos trabalhadores, embora queria-se universal e intencionasse educar pela racionalização e aceitação do princípio da escola ativa (GRAMSCI, Cad. 12, § 2 2000a, p. 45), relação não passiva entre educador-educando (SOARES, 2000, p. 192-208); b) a tradicional: para poucos e não se articulava às contradições; "desinteressada", mas "formativa"; autoritária, instalava a passividade na relação educador-educando, mas educava porque transmitia o legado cultural de uma para outra geração; c) a resultante da reforma fascista de Gentile (1923): ideava o Estado como ético e educador da nação, instaurava a fidelidade dos educadores ao fascismo, a passividade ético-política nos educandos, com a educação profissional e religiosa, promotora da separação entre dirigentes e dirigidos.

Gramsci interpretou o contexto escolar italiano da época como o de refluxo da escola tradicional e difusão dos diferentes tipos de escolas profissionais. As primeiras assumiam o compromisso de conservar a tradição greco-romana, mas tendiam a desaparecer ou ficar reduzidas. As profissionalizantes tornavam-se mais especializadas e

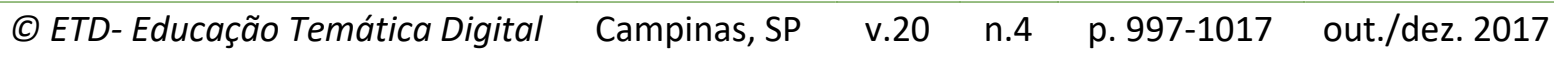


colaboravam para pré-definir o destino dos trabalhadores (GRAMSCI, Cad. 12, § 1, 2000a, p. 33 e 49).

Da constatação de que a cultura era privilégio de poucos selecionados pelos injustos exames oficiais, Gramsci defendeu na juventude uma escola única para todos, humanista, de cultura geral, que unificasse "saber" e "fazer" no processo de formação. Seria uma escola "desinteressada"7 do trabalho, voltada à formação cultural, propedêutica, não profissionalizante precocemente, em oposição às iniciativas governamentais que, em 1916, propuseram "interesseiramente fundir a escola com a oficina simplesmente para utilizar os alunos na reprodução de munições que a guerra destrói" (NOSELLA, 1992, p. 18).

Com formação ampla, sem rebaixamento cultural paternalista (acreditava Gramsci que com condições adequadas os subalternos poderiam aprender o que os dominantes aprendem), a escola desinteressada visava a formar quadros ao futuro Estado socialista. Isso marcou a intervenção do sardo nas experiências educativas "não formais" que empreendeu, inclusive no cárcere de Ústica (JESUS, 2005, p. 89-115). Nelas, amadureceu a concepção de que se deve formar interessadamente (superar o capitalismo), mas com cultura desinteressada, anti sectária, historicista e humanista, uma via para formar sujeitos aptos a exercer a hegemonia.

Na prisão, Gramsci refletiu sobre as escolas socialistas de formação onmilateral, cujo exemplo histórico era a "escola única do trabalho" da reforma escolar Russa, incorporada ao programa do PC-Russo no 8o Congresso (março-1919). Protagonizada por Krupskaia e presente em Pistrak, essa escola buscava forjar uma nova cultura, geral e politécnica, com o desenvolvimento mental, físico, criativo (interesse da escola nova) e dos sentidos.

Dos Conselhos de Fábrica ao cárcere, as formulações educativas gramscianas amadureceram, tornando-se indispensáveis à construção de uma nova civilização ${ }^{8}$.

Gramsci fincou as bases da escola unitária no trabalho moderno, algo aparentemente ${ }^{9}$ fora dela. Isso porque a indústria reordenou a conduta dos indivíduos e da sociedade, formou-os psicofisicamente de acordo com a produção (GRAMSCI, Cad. 22 2001, p. 237-282), impôs disciplina e racionalização, algo positivo ao sardo, mas negativo também por se fixarem abstrata e autoritariamente (fazer sem saber). A união trabalhoescola, presente em Marx e Engels, tornou-se em Gramsci eixo da escola unitária, seu motor de transformação.

Na escola unitária, "a teoria e o trabalho estão estritamente unidos" (MANACORDA, 1990, p. 243) e seu "advento significa o início de novas relações entre trabalho intelectual e trabalho industrial não apenas na escola, mas em toda a vida social" (GRAMSCI, Cad. 12, § 1 - 2000a, p. 40). Essa "escola única inicial de cultura geral, humanística, formativa, equilibra 
de modo justo o desenvolvimento da capacidade de trabalhar manualmente e o trabalho intelectual" (Idem, Ibidem, p. 33); posteriormente, passa-se "a uma das escolas especializadas ou ao trabalho produtivo" (Idem Ibidem, p. 34). Se na primeira fase da escola (primária) o trabalho como princípio educativo é mais implícito e indireto, pois pretende compreender as noções científicas elementares que conformam as sociedades modernas, na segunda (média) a determinação é mais direta, pois deve explicitar como a ciência se transformou em força produtiva e dominar os fundamentos das múltiplas técnicas de produção (politecnia), chave ao desenvolvimento das sociedades atuais (SAVIANI, 2014).

O objetivo almejado é promover condições ao educando para superar o reino da necessidade pelo da liberdade; sem espontaneismo, pois exige disciplina e intervenção; sem autoritarismo e abstração, porquanto se parte das contradições da realidade concreta. 0 intuito é suscitar a reforma moral e intelectual, formar intelectuais de diferentes tipos, orgânicos às classes subalternas, para erigirem um novo bloco histórico, processo em que "a instituição escolar é campo da construção de hegemonias" (NOSELLA, 2013, p. 49).

Essa formulação é tradução do marxismo originário para as sociedades ocidentais. A proposta educativa de Marx e Engels é do século XIX, contexto do "Estado restrito"; visava à formação "tecnológica de teoria e prática" (MANACORDA, 1991), articulada à educação "mental" e "corporal" (MARX; ENGELS, 1978, p. 223). "Na teoria em que o Estado é uma 'máquina' de repressão da burguesia, que deveria ser quebrada para derrubar o capitalismo ('fórmula de 1848 '), a educação não tinha um lugar importante" (SOARES, 2006, p. 339). Gramsci faz a "virada nesse modo de entender as idéias e a cultura" (Idem, Ibidem) com a escola unitária no século XX, no curso da ampliação do Estado e mirando a elevação cultural dos subalternos, o que exige reordenamento do "eu" interior, pois "cada um transforma a si mesmo na medida em que transforma todo o conjunto de relações do qual ele é o ponto central" (GRAMSCl, Cad. 10 - Parte II, § 54, 1999, p. 413).

O termo "unitário" indica uma só escola para todos ${ }^{10}$ e também que nela se articule "saber e fazer" (MARTINS, 2000). O foco é no desenvolvimento omnilateral do homem como produtor da própria história, e não nos instrumentos e técnicas, como parece enfatizar o termo "politécnico" (NOSELLA, 2007, p. 146). Assim, "O 'princípio unitário ultrapassa a escola como instituição e se relaciona à luta pela igualdade social, para superar as divisões de classe, que se expressam na separação entre trabalho industrial e trabalho intelectual e dividem a sociedade entre governantes e governados." (SOARES, 2006, p. 339340)

Ao trabalhar com pares dialéticos (espontaneismo-coerção, conformismo-ativismo, por exemplo), como é próprio da filosofia da práxis (entre idealismo e materialismo vulgar), Gramsci apresenta o método da escola unitária, fundado no trabalho moderno desde a infância. Respeitando-Ihe o desenvolvimento, educa-a para criar hábitos civilizatórios ao

$\begin{array}{llllll}\text { (C) ETD-Educação Temática Digital } & \text { Campinas, SP } & \text { v.20 } & \text { n.4 } & \text { p.997-1017 } & \text { out./dez. } 2017\end{array}$


exercício da autonomia quando adulto, constituindo-se como segunda natureza (catarse) $)^{11}$.

Se "escola é instrumento para elaborar intelectuais de diversos níveis" (GRAMSCl, Cad. 12, § 1 - 2000a, p. 19), para atuarem segundo a autonomia dos indivíduos, obviamente Gramsci descarta os dotes naturais (precoces inclinações profissionais), e a assume a noção de ser humano como bloco histórico ${ }^{12}$. Com ela, defende o estímulo ao aprendizado articulado à dinâmica da realidade, com disciplina nos estudos e nas práticas educativas, orientadas pela racionalização para forjar uma natureza humana não subalterna (disciplina e autonomia). É um método não espontaneista, como o de Rousseau (crítico ao autoritarismo do jesuitismo pedagógico e defensor da liberdade do educando) e da Pedagogia Nova (da qual Gramsci desconfia, mas reconhece críticas à Pedagogia Tradicional), pois ao bel prazer, o discente se formará como ser caótico, síncrese das influências do ambiente. Exige-se, pois, autoridade do educador para intervir no processo de formação, instigando o aprendizado (com seminários, por exemplo) e almejando, ao partir do senso comum, alcançar a concepção filosófica (racionalização) necessária ao ser criativo, ativo e autônomo éticopoliticamente, condições de superação da subalternidade. O viés metodológico da escola unitária prima por mais "dogmatismo" e intervenção (imposição de disciplina moral e intelectual) no ponto de partida da formação (infância) e mais autonomina e espírito criativo na chegada (adulto), isto é, autodisciplina e liberdade, pois o processo educativo consiste em fazer avançar o educando "da anomia à autonomia pela mediação da heteronomia" (SAVIANI, 2008a, p. 70).

$\mathrm{Na}$ escola unitária, os conteúdos são valorizados e articulados à síntese trabalho moderno-formação humanística. O educando deve apropriar conhecimentos historicamente produzidos e sintetizados nos clássicos, que guardam composições do desenvolvimento do espírito humano. Assim, "O estudo das ciências naturais, assinala Gramsci, visa introduzir as crianças na societas rerum, e pelas ciências sociais elas são introduzidas na societas hominum" (SAVIANI, 2007a, p. 160), conhecimentos que permitem compreender e dominar a si e a vida social, mas são tomados pela burguesia. Com um "currículo escolar de vários níveis, de acordo com a idade e com o desenvolvimento intelectual e moral dos alunos" (GRAMSCl, Cad. 12, § 1 - 2000a, p. 36), deverá ainda ser conteúdo os fundamentos científicos do trabalho, daí reestruturar a escola para o educando ter domínio teórico e prático dos processos de produção social, marcados pela ciência e tecnologia como força produtiva.

O objetivo da escola unitária é formar intelectuais orgânicos às classes subalternas e, amplamente, possibilitar a todos o acesso ao conhecimento e domínio da dinâmica social, estimular a superação da passividade e construir condições para governarem ou controlar quem governa. Ou seja, possibilitar aos subalternos saber o que a classe hegemônica sabe, com a escola assumindo "a tarefa de inserir os jovens na atividade social, depois de tê-los

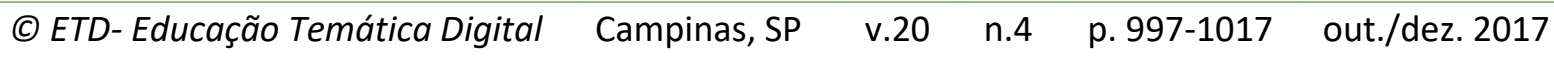


elevado a um certo grau de maturidade e capacidade para a criação intelectual e prática e a uma certa autonomia na orientação e na iniciativa" (GRAMSCl, Cad. 12, § 1, 2000a, p. 36), para, com "um tipo único de escola preparatória (primária-média) [conduzir] o jovem até os umbrais da escolha profissional, formando-o, durante este meio tempo, como pessoa capaz de pensar, de estudar, de dirigir ou de controlar quem dirige" (Idem, Ibidem, p. 49). De modo que sejam homem integrais, como Leonardo, síntese entre ciência e cultura humanística ${ }^{13}$.

Mas isso tudo depende de certa organização. A proposição de escola unitária é a de uma escola básica, laica, financiada pelo Estado (macro educador social), pública, gratuita, em tempo integral, com professores cuja autoridade reside na boa formação e na proximidade aos alunos (coerção-afeto). Dadas as dificuldades de os subalternos lidarem com a escola, pois não foram formados para isso (GRAMSCI, Cad. 12, § 1, 2000a, p. 37-38), a escola deverá ter prédios aptos a receberem diversas atividades e com adequado material didático.

Assim, ao nível superior chegariam indivíduos não profissionalizados precocemente, com a elevada consciência de si e do mundo, que seriam capazes de desenvolver a aptidão ao trabalho que, autonomamente, julgarem adequada para si. A universidade seria centro produtor e difusor de uma nova cultura para construir a nova civilização, com capacidade autocrítica e crítica ao desenvolvimento social, para além da retórica e de verdades instituídas, apta a produzir e difundir valores humanistas e a tomar os problemas concretos como objeto de pesquisa. Até porque a "'escola' de alta cultura, de elaboração crítica e científica [é] imprescindível a qualquer hegemonia." (JESUS, 2005, p. 75)

\section{A TRADUÇÃO DA ESCOLA UNITÁRIA DE GRAMSCI POR SAVIANI}

Dermeval Saviani é um marxista brasileiro e formulador originário da pedagogia histórico-crítica ${ }^{14}$. Lê o legado de Marx e Engels pelas lentes leninistas e gramscianas. Mas o Gramsci de Saviani é diferente dos liberais, é o da luta de classes ${ }^{15}$, intelectual orgânico às classes subalternas, marcado pela tradução que Lênin produziu do marxismo originário.

Se entre 1960-70, Saviani sofreu influência da fenomenologia e do existencialismo (cf. SAVIANI, 1978), posteriormente a identidade marxista gramsciana nele prevaleceu e transparece na pedagogia histórico-crítica. Ele reconhece que "as fontes específicas da pedagogia histórico-crítica se reportam às matrizes teóricas do materialismo histórico representadas, basicamente, por Marx e Gramsci" (SAVIANI, 2013a, p. 77). Ela parte do 
"método da economia política", o movimento que vai da síncrise ("a visão caótica do todo") à síntese ("uma rica totalidade de determinações e relações numerosas") pela mediação da análise ("as abstrações e determinações simples") constitui uma orientação segura tanto para o método científico como para o método de ensino. E o termo "catarse", que denomina o quarto passo do método proposto, o qual se constitui no momento culminante do processo pedagógico, é entendido na acepção gramsciana de "elaboração superior da estrutura em superestrutura na consciência dos homens". (SAVIANI, 2013a, p. 76-77)

Mais do que a autoidentificação de Saviani, são as intervenções que produziu na educação e na pesquisa em educação que autorizam a dizer que a pedagogia que formulou é marxista, como a de Gramsci, porque: a) compreende a educação como imanente à produção do ser social, "como uma atividade mediadora no interior da prática social global" (SAVIANI, 2015b, p. 35) e entende o "trabalho educativo [como] o ato de produzir, direta e intencionalmente, em cada indivíduo singular, a humanidade que é produzida histórica e coletivamente pelo conjunto dos homens" (SAVIANI, 2008a, p. 13); b) assume o trabalho como princípio educativo "Inspirado nas reflexões de Gramsci sobre [...] escola unitária" (SAVIANI, 207, p. 159); c) compromete-se com a superação do capitalismo ao tomar a luta de classes como articuladora do processo educativo (SAVIANI, 2013b, p. 26). Por isso, muitos reconhecem Saviani como marxista-gramsciano. Mas, o que fez de Gramsci não foi transposição do seu legado ao contexto nacional e sim tradução da escola unitária ${ }^{16}$.

Saviani foi perguntado recentemente sobre isso ${ }^{17}$ : "O senhor considera que a pedagogia histórico-crítica é uma tradução da escola unitária?". Ao que respondeu: "Podese dizer isso a posteriori, pois o meu contato com Gramsci foi durante o processo de formulação dessa teoria pedagógica e não antes dele". E prosseguiu: "Essa é sua leitura, pois há os que não veem essa relação entre pedagogia histórico-crítica e Gramsci."

De fato, entre as décadas de 1960-70, a produção acadêmica e o trabalho educativo de Saviani, como no Colégio Sion (SAVIANI, 2012), foram empreendidos sem que ele tivesse contato com Gramsci. Vivia-se no Brasil "o boom gramsciano de meados dos anos de 1970" (SECCO, 2002, p. 46). Quando Saviani conheceu a produção do sardo, percebeu que havia correspondência entre o que tinham feito. Em 1978, em disciplina do Doutorado em Educação da PUC-SP, fez "estudo monográfico do pensamento e das obras de Gramsci buscando extrair os elementos teóricos que nos permitissem compreender de forma crítica os problemas da educação brasileira" (SAVIANI, 2012, p. 6). Considerado "1979 como um marco importante na formulação da pedagogia histórico-crítica" (SAVIANI, 2012, p. 6), cada vez mais o sardo se incorporou às formulações de Saviani e este se tornou pioneiro na introdução daquele no campo da educação no Brasil. Além disso, alguns doutorandos do referido curso tornaram-se referência na área (SAVIANI, 2008a, p. 61-63) e ajudaram a difundir Gramsci, como Paolo Nosella. 
Dois anos depois, na coletânea com textos de 1971 a 1979 (Educação: do senso comum à consciência filosófica - SAVIANI, 1982), Saviani, na Introdução, citou passagens de Gramsci e no capítulo final apresentou "inspiração gramsciana" (SAVIANI, 2013a, p. 64) ao abordar o contexto nacional pela distinção entre aspecto estrutural (movimento orgânico) e conjuntural $^{18}$, além do que o título reporta-se à problemática gramsciana. A análise da educação por Saviani, neste e em outros textos, é mediada pela tradução dos conceitos de Gramsci, que particularmente se revela na: a) leitura da escola como estratégica à passagem ao socialismo; b) crítica às teorias educacionais vigentes; c) defesa de um específico processo de formação; d) método de trabalho educativo; e) tipo de organização escolar sugerida.

Saviani não vê a escola somente como reprodutora da vida social, como os reprodutivistas ${ }^{19}$. Ela pode ser "crítica" ao "coloca[r] a educação a serviço das forças que lutam para transformar a ordem vigente" (SAVIANI, 2005, p. 35), mesmo concebendo-se como condicionada, pois não é o "determinante principal das transformações sociais, [é] elemento secundário e determinado [que] se relaciona dialeticamente com a sociedade [mas] não deixa de influenciar o elemento determinante [é] por vezes decisivo no processo de transformação." (SAVIANI, 2013c, p. 230)

Sobre as teorias educacionais em evidência na década de 1980, Saviani avaliou-as e destacou, de um lado, positivos aspectos da pedagogia tradicional (importância do conteúdo, centralidade do professor, racionalização do ensino etc.) - justamente ela que foi acusada pela "Escola Nova [de] pré-científico, anticientífico, dogmático" (SAVIANI, 1983, p. 49) - e, de outro, demonstrou que a tão em moda pedagogia nova, da forma como se apresentou no contexto nacional, não só não era democrática (Idem, Ibidem, p. 53-53), como colaborou para cimentar a hegemonia dominante (Idem, Ibidem, p. 54-61). Essa interpretação foi inovadora à época, porque a Escola Nova era celebrada, inclusive por progressistas, na mesma intensidade das críticas dirigidas à pedagogia tradicional. Saviani utilizou a metáfora leniniana da "teoria da curvatura da vara" para descrever o processo analítico que sustentou a formulação da pedagogia histórico-crítica, para além da tradicional e nova, algo similar ao que Gramsci fez em relação às teorias educacionais.

Assim, "para além dos métodos tradicionais e novos, visando superar por incorporação as contribuições dessas duas tendências pedagógicas" (SAVIANI, 2012, p. 8), Saviani formulou uma nova pedagogia, que se apresentou nacionalmente como contribuição ao avanço na construção de outra hegemonia, que "só pode ser formulada do ponto de vista dos interesses dominados" (SAVIANI, 1983, p. 35), pois a educação deve ser a passagem da desigualdade no ponto de partida à igualdade na chegada. É uma pedagogia crítica, entendido este termo como o que tem "a percepção dos condicionantes objetivos [do que resulta] encarar a educação remetendo-a sempre aos determinantes sociais, à

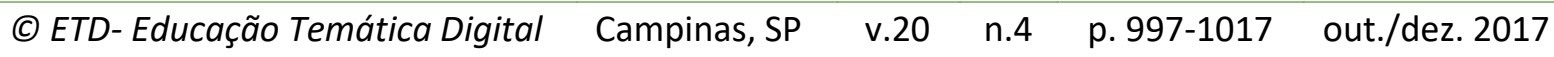


estrutura sócio-econômica que condiciona a forma de manifestação do fenômeno educativo" (SAVIANI, 1983, p. 9). Isso está conectado ao trabalho de formulação da escola unitária: o contexto é diferente, os objetos de análise são próximos, mas o princípio teórico, as finalidades ético-políticas e os métodos são similares, o que possibilita a tradução.

A lapidação dessa teoria crítica ganhou lugar em Pedagogia histórico-crítica: primeiras aproximações (SAVIANI, 2008a), de 1991. Nele, a escola unitária aparece em adiantada tradução, o que foi se consolidando em outros textos e intervenções no cenário da educação e da pesquisa educacional. É evidenciado no referido livro, tal como em Gramsci, que na escola deve-se valorizar a apropriação do conhecimento por parte dos educandos, mas conhecimento sistematizado, sobretudo, nos clássicos ${ }^{20}$, que se tornam "critério útil para a seleção dos conteúdos do trabalho pedagógico" (SAVIANI, 2008a, p. 21). Para Saviani, "A escola existe para propiciar a aquisição dos instrumentos que possibilitam o acesso ao saber elaborado" (Idem, Ibidem, p. 23), tem o "papel de possibilitar o acesso das novas gerações ao mundo do saber sistematizado, do saber metódico, científico" (SAVIANI, 2008a, p. 97), o que era indicado por Gramsci à escola unitária, pois assim, com os subalternos sabendo o que os dominantes sabem, seria possível avançar com a superação do capitalismo.

Percebe-se que no processo de formação, a dinâmica que se estabelece na relação professor-aluno, tanto para Gramsci quanto para Saviani, é a de um movimento descendente do professor (da síntese à síncrese) e ascendente do aluno (da síncrese à síntese). O que não significa que o professor não aprenda, mas que sua função primordial é elevar a consciência do aluno ao patamar que possibilite compreender a si e ao mundo, com o saber sistematizado. Obviamente, orientado pela pedagogia histórico-crítica, o professor aprende, porque ela exige isso dele: aprender o que sabe o aluno, aprender a realidade, aprender o saber elaborado, enfim, que avance na própria aprendizagem ao promover a aprendizagem dos alunos.

Em relação ao método, em Escola e democracia, de 1983, encontra-se a tradução que Saviani produziu da escola unitária. Os passos ou momentos do método de ensino apresentado tem proximidade com o método gramsciano. Contudo, na obra do sardo não se encontram tão definidos, pois isso foi resultado do trabalho de tradução de Saviani. 0 método da pedagogia histórico-crítica, dialeticamente superando a pedagogia tradicional (Herbart) e nova (Dewey), é formulado em 5 momentos: a) parte-se da prática social, dos problemas que nela emergem e que são comuns a professores e alunos, mas entendidos diferentemente por eles; b) problematiza-se os problemas ${ }^{21}$ identificados, indicando questões a superar pela práxis, com a contribuição da educação; c) fornecem-se instrumentos teóricos (clássicos) e práticos para equacionar a problematização; d) instrumentalizados, os alunos terão condições de elevar a consciência sobre si e sobre o

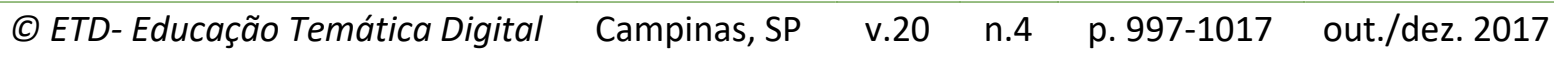


mundo, do que deverá decorrer outra postura na prática social, que é a catarse (CARDOSO; MARTINS, 2014), conceito "importado" de Gramsci, mas empregado de modo criativo por Saviani para indicar o ponto culminante do processo educativo; e) com a catarse, a nova consciência (sintética) e a decorrente ação social passam a ser internalizadas nos sujeitos como segunda natureza, o que os direcionarão a terem outra atitude na prática social, da qual nunca saíram.

Apesar desses cinco passos ou momentos estarem claramente estabelecidos, é mister destacar que eles não são universais, porquanto não há na pedagogia histórico-crítica uma metodologia formalmente estabelecida. Importa para a pedagogia formulada por Saviani que

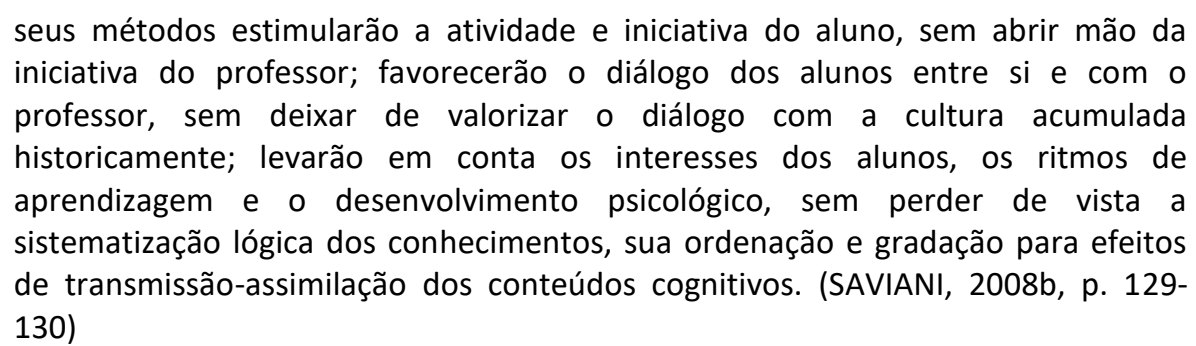

Assumindo-se como pedagogia marxista-gramsciana, "os significados das categorias e dos conceitos variam de acordo com a situação concreta" (MARTINS, 2008a, p. 285). Todavia, a variação tem como limite o objetivo de produzir a catarse, pois é decorrente do enfrentamento de contradições concretas, que mudam de contexto a contexto ${ }^{22}$.

A organização escolar sugerida pela pedagogia histórico-crítica é próxima a da escola unitária: "em Gramsci que me inspirei para indicar o caminho para a construção de um currículo escolar adequado às condições atuais próprias desse período de transição da forma social capitalista para uma sociedade socialista" (SAVIANI, 2012, p. 10). Como Saviani concebe a escola como o mais desenvolvido espaço historicamente construído para ensinaraprender, as atividades nucleares do currículo devem se centrar na episteme, complementada por atividades extra-nucleares, orientadas à doxa e à sofia (SAVIANI, 2008a, p. 14,15 e 87$)$.

Forjada originariamente por Saviani, a pedagogia histórico-crítica propõe, como em Gramsci, uma única escola para todos, com conteúdo e método unitário. Hoje, ela se encontra sendo desenvolvida coletivamente, com colaboradores que a referencia na psicologia histórico-cultural, como Lígia M. Martins, Newton Duarte e Ana Carolina G. Marsiglia, até porque tem "afinidades, no que se refere às suas bases psicológicas, com a psicologia histórico-cultural desenvolvida pela Escola de Vigotski" (SAVIANI, 2008b, p. 185). 


\section{5 À GUISA DE CONCLUSÃO}

No exposto, procurou-se evidenciar a tese de que Saviani traduziu a escola unitária de Gramsci na pedagogia histórico-crítica. Se ela está sendo desenvolvida por trabalho coletivo com outras matrizes teóricas marxistas, na origem, Ihe foi Gramsci a principal referência.

A tradução produzida por Saviani revela o que ele próprio afirmou na palestra de 21/05/2017 (cf. nota XVII), que embora Gramsci possa ser identificado na pedagogia histórico-crítica de diversas maneiras, esta tem com ele, particularmente, "afinidades de propósitos e o mesmo viés metodológico", e foi desenvolvida a partir de "análises orientadas por conceitos e categorias elaborados por Gramsci, que se incorporaram a ela".

Se Saviani encontrou Gramsci no percurso de elaboração da pedagogia históricocrítica, na medida em que avançou neste processo, as contribuições do sardo tornaram cada vez mais explícitas nas intervenções no campo da educação, como em recentes livros: História das ideias pedagógicas no Brasil (SAVIANI, 2007b), de 2007, e Pedagogia no Brasil (SAVIANI, 2008b), de 2008. Saviani procedeu com Gramsci como este procedeu com Marx: traduziu! Se tradução é fundamento da filosofia da práxis, Saviani, com capacidade crítica e criativa, soube traduzir na pedagogia histórico-crítica a escola unitária de Gramsci.

\section{REFERÊNCIAS}

AGGIO, Alberto. O Gramsci que "conhecemos" e o que ele inspirou. Site Gramsci e o Brasil, dezembro de 2015. Disponível em:

http://www.acessa.com/gramsci/?page=visualizar\&id=1886 . Acesso em: 6 mai. 2017.

BETTI, G. Escuela, educación y pedagogía en Gramsci. Barcelona: Martínez Roca, 1981.

BIANCHI, Álvaro. O laboratório de Gramsci: filosofia, história e política. São Paulo: Alameda, 2008.

BIANCHI, Álvaro. Lênin e a filosofia: notas para uma leitura metodológica. Disponível em: https://www.e-

science.unicamp.br/marxismo/admin/projetos/documentos/documento 579 Lenin.pdf. Acesso em: 20 fev. 2017a.

BIANCHI, Álvaro. Um sardo no mundo grande e terrível. Revista Cult, ano 20, n.222, p. 2630, abr./2017b.

BOBBIO, Norberto. O conceito de sociedade civil. Trad. de C. N. Coutinho, 2. ed. Rio de Janeiro: Graal, 1982.

BOOTHMAN, Derek. "Tradutibilidade" e "Traduação". In: LIGUORI, G. e VOZA, P. (Org.).

Dicionário gramsciano (1926-1937). São Paulo: Boitempo, 2017. p. 782-784 e p. 779-782.

CARDOSO, Mário M. R; MARTINS, Marcos F. A catarse na Pedagogia Histórico-Crítica.

HISTEDBR On-line, Campinas, no 57, p. 146-164, jun.2014. Disponível em:

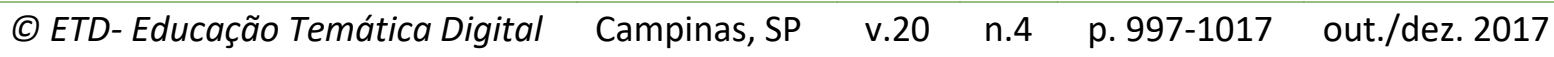


http://periodicos.sbu.unicamp.br/ojs/index.php/histedbr/article/view/8640409 . Acesso em: 23 abr. 2017.

COUTINHO, Carlos N. Gramsci: um estudo sobre seu pensamento político. Rio de Janeiro: Civilização Brasileira, 1999.

COUTINHO, Carlos N. e KONDER, L. Notas sobre Antonio Gramsci. In: GRAMSCI, A. Concepção dialética da história. 10. ed. Rio de Janeiro: Civilização Brasileira, 1995.

FIORI, Giuseppe. A vida de Antonio Gramsci. Rio de Janeiro: Paz e Terra, 1979.

GRAMSCl, Antonio. Cadernos do cárcere - v. 1 - Antonio Gramsci: introdução ao estudo da filosofia; a filosofia de Benedetto Croce. Rio de Janeiro: Civilização Brasileira, 1999.

GRAMSCl, Antonio. Cadernos do cárcere - v. 2 - Antonio Gramsci: os intelectuais; o princípio educativo; jornalismo. Rio de Janeiro: Civilização Brasileira, 2000a.

GRAMSCI, Antonio. Escritos políticos - volume 1 - 1910-1920. Rio de Janeiro: Civilização Brasileira, 2004a.

GRAMSCI, Antonio. Escritos políticos - volume 2 - 1921-1926. Rio de Janeiro: Civilização Brasileira, 2004b.

GRAMSCI, Antonio. Cartas do Cárcere - volume 1 - 1926-1930. Rio de Janeiro: Civilização Brasileira, 2005a.

GRAMSCI, Antonio. Cartas do Cárcere - volume 2 - 1931-1937. Rio de Janeiro: Civilização Brasileira, 2005b.

JESUS, Antônio T. de. 0 pensamento e prática escolar de Gramsci. 2a ed. Campinas-SP: Autores Associados, 2005.

LACORTE, Rocco. Sobre alguns aspectos da "tradutibilidade" nos Cadernos do Cárcere de Antonio Gramsci e algumas das suas implicações. Educação e Filosofia, Uberlândia, v. 28, n. 55, p. 59-98, jan.jun. 2014. Disponível em:

http://www.seer.ufu.br/index.php/EducacaoFilosofia/article/view/24962/15246 . Acesso em: 5 ago. 2016.

LÊNIN, Vladimir I. Cadernos filosóficos. Buenos Aires: Ediciones Estudio, 1972.

LÊNIN, Vladimir I. Obras escolhidas. São Paulo: Editora Alfa-Ômega, 1980. (Tomo 3)

LÊNIN, Vladimir I. As três fontes e as três partes constitutivas do marxismo. 5. ed. São Paulo: Global, 1985.

LO PIPARO, Franco. A linguística e o não marxismo de Gramsci. Site Gramsci e o Brasil, junho-2008. Disponível em: http://www.acessa.com/gramsci/?page=visualizar\&id=941 . Acesso em: 15 mar. 2017.

MANACORDA, Mario A. O princípio educativo em Gramsci. Porto Alegre: Artes Médicas, 1990.

MANACORDA, Mario A. Marx e a pedagogia moderna. São Paulo: Cortez; Campinas: Autores Associados, 1991.

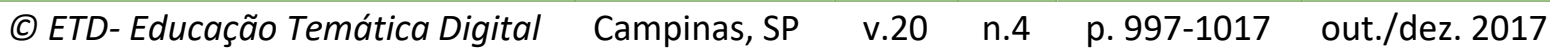


MARTINS, Marcos F. Ensino técnico e globalização: cidadania ou submissão. Campinas-SP: Autores Associados, 2000.

MARTINS, Marcos F. Marx, Gramsci e o conhecimento: ruptura ou continuidade? CampinasSP: Autores Associados; Americana-SP: UNISAL, 2008a.

MARTINS, Marcos F. Sociedade civil e "Terceiro Setor": apropriações indébitas do legado teórico-político de Gramsci. Revista de Filosofia Aurora, Curitiba, v. 20, n. 26, p. 75-100, jan./jun. 2008b. Disponível em:

http://www2.pucpr.br/reol/pb/index.php/rf?dd1=1993\&dd99=view\&dd98=pb . Acesso em: 8 mar. 2017.

MARTINS, Marcos F. Gramsci, filosofia e educação. Práxis Educativa, Ponta Grossa, v. 8, n. 1, p. 13-40, jan./jun. 2013. Disponível em:

http://www.revistas2.uepg.br/index.php/praxiseducativa/article/view/5369/3466 . Acesso em: 20 mar. 2017.

MARTINS, Marcos F. Educação e ensino no marxismo originário. In.: FRANCA, G. C. e LEITE, K. C. Cidade, natureza, educação: olhares marxistas. São Paulo: Xamã, 2016, p. 183-198.

MARX, Karl; ENGELS, Friedrich. Crítica da educação e do ensino. Trad. de A. M. Rabaça. Lisboa: Moraes, 1978.

MENESES, Jaldes R. Vocabulário gramsciano - tradução e tradutibilidade. site Gramsci e o Brasil. 2006. Disponível em:

http://www.acessa.com/gramsci/texto visualizar.php?mostrar vocabulario=mostra\&id=66 Acesso em: 20 abr. 2017.

NOSELLA, Paolo. A escola de Gramsci. Porto Alegre: Artes Médicas, 1992.

NOSELLA, Paolo. Trabalho e perspectivas de formação dos trabalhadores: para além da formação politécnica. RBE, v. 12, no. 34, jan./abr. 2007, p. 137-181. Disponível em: http://www.scielo.br/pdf/rbedu/v12n34/a11v1234.pdf . Acesso em: 18 abr. 2017.

NOSELLA, Paolo. Controvérsias marxistas sobre a leitura e recepção de Gramsci na educação brasileira. In.: LOMBARDI, J. C., MAGALHÃES, L. D. R. e SANTOS, W. S. S. (Orgs.). Gramsci no limiar do século XXI. Campinas-SP: Librum, 2013, p. 45-59.

RAGAZZINI, Dario. A teoria da personalidade na sociedade de massa: a contribuição de Gramsci. Trad. de M. L. Menon. Campinas: Autores Associados, 2005.

SAVIANI, Dermeval. Educação brasileira: estrutura e sistema. São Paulo: Saraiva, 1978.

SAVIANI, Dermeval. Educação: do senso comum à consciência filosófica. 2. ed. São Paulo: Cortez e Autores Associados, 1982.

SAVIANI, Dermeval. Escola e democracia: teorias da educação, curvatura da vara, onze teses sobre educação política. São Paulo: Cortez e Autores Associados, 1983.

SAVIANI, Dermeval. Apresentação. In: WACHOWICZ, L. A. 0 método dialético na didática. Campinas: Papirus, 1989. 
SAVIANI, Dermeval. Trabalho e educação: fundamentos ontológicos e históricos. Revista Brasileira de Educação, v. 12, n. 34, jan./abr. 2007a. Disponível em: http://www.scielo.br/pdf/rbedu/v12n34/a12v1234.pdf . Acesso em: 10 mai. 2017.

SAVIANI, Dermeval. História das ideias pedagógicas no Brasil. Campinas: Autores Associados, 2007b.

SAVIANI, Dermeval. Pedagogia histórico-crítica: primeiras aproximações. 10 ed. rev. Campinas-SP: Autores Associados, 2008a.

SAVIANI, Dermeval. A pedagogia no Brasil: história e teoria. Campinas-SP: Autores Associados, 2008b.

SAVIANI, Dermeval. Origem e desenvolvimento da pedagogia histórico-crítica. 2012. Disponível em:

https://www.fe.unicamp.br/eventos/ged/histedbr2016/xhistedbr/paper/view/887/181 . Acesso em: 6 mai. 2017.

SAVIANI, Dermeval. Gramsci e a educação brasileira. In.: LOMBARDI, José C., MAGALHÃES, Lívia D. R. e SANTOS, W. S. (Orgs.). Gramsci no limiar do século XXI. Campinas-SP: Librum Editora, 2013a, p. 60-79.

SAVIANI, Dermeval. A pedagogia histórico-crítica, as lutas de classe e a educação escolar. Germinal: marxismo e educação em debate, Salvador, v. 5, n. 2, p. 25-46, dez. 2013b. Disponível em: file:///C:/Users/GPTeFE1/Downloads/9697-26953-1-PB.pdf . Acesso em: 13 abr. 2017.

SAVIANI, Dermeval. Escola e democracia: para além da "teoria da curvatura da vara". Germinal: marxismo e educação em debate, Salvador, v. 5, n. 2, p. 227-239, dez.2013c. Disponível: www.portalseer.ufba.br/index.php/revistagerminal/article/.../9713/7100 . Acesso em: 28 mai. 2014.

SAVIANI, Dermeval. A nova Internacional: Michael Löwy, Franck Seguy, Alfredo Saad e Dermeval Saviani. 2h35. Publicado em: 01/12/2014. Disponível em:

https://www.youtube.com/watch?v=EyQ5qWKNy30 . Acesso em: 03 mai. 2017.

SAVIANI, Dermeval. Catarse na pedagogia histórico-crítica: a concepção de Saviani. Crítica Educativa (Sorocaba/SP), v. 1, n. 1, p. 163-217, jan. /jun. 2015a. Disponível em: http://www.criticaeducativa.ufscar.br/index.php/criticaeducativa/article/view/29/177. Acesso em: 02 mai. 2017.

SAVIANI, Dermeval. O conceito dialético de mediação na pedagogia histórico-crítica em intermediação com a psicologia histórico-cultural. Germinal: marxismo e educação em debate, Salvador, v. 7, n. 1, p. 26-43, jun. 2015b. Disponível em:

https://portalseer.ufba.br/index.php/revistagerminal/article/view/12463/9500 . Acesso em: 03 mai. 2017.

SAVIANI, Dermeval. História do tempo e tempo da história: estudos de historiografia e história da educação. Campinas-SP: Autores Associados, 2015c.

SCHIRRÙ, Giancarlo. Antonio Gramsci e a linguística. Revista Cult, Editora Bregantini, ano 20, no 222, p.40-43, abr./2017.

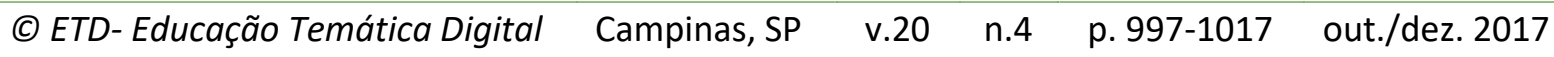


SECCO, Lincoln. Gramsci e o Brasil: recepção e difusão de suas idéias. São Paulo: Cortez, 2002.

SILVEIRA JÚNIOR, Adilson A. Gramsci e o "problema da tradutibilidade" na filosofia da práxis. Crítica Marxista, n. 40, p. 63-82, 2015. Disponível em: http://www.ifch.unicamp.br/criticamarxista/arquivos biblioteca/artigo2016 $0803 \quad 1237$ 18.pdf. Acesso em: 2 ago. 2016.

SNYDERS, Georges. Escola, classe e luta de classes. Lisboa: Moraes, 1976.

SOARES, Rosemary D. Gramsci, o Estado e a escola. Ijuí: Unijuí, 2000.

SOARES, Rosemary D. Gramsci e o debate sobre a escola pública no Brasil. Cadernos CEDES, Campinas, v. 26, no 70, p. 329-352, set./dez. 2006.

STACCONE, Giuseppe. Gramsci - 100 anos: revolução e política. Petrópolis: Vozes, 1995.

\footnotetext{
1 "o cotidiano numa Itália recentemente unificada, habitada por uma miríade de dialetos e uma escassa difusão do idioma oficial; as exigências do intenso intercâmbio político com os movimentos comunistas estrangeiros; as requisições de apreensão e difusão, na militância e atividade jornalística, da literatura socialista internacional; a necessidade, durante a reclusão, de empregar em termos cifrados boa parte do vocabulário marxista (e leninista), em face da censura imposta; a recorrência, também no cárcere, aos exercícios de tradução como estratégia para se ocupar e suportar o isolamento forçado" (SILVEIRA JÚNIOR, 2015, p. 64). Além desses, cabe mencionar a "fundação da União Soviética em 1923, com bases em diferentes identidades nacionais dos povos soviéticos, cada uma delas estabelecida com base em critérios linguísticos" (SCHIRRÚ, 2017, p. 42) e o "interesse pelo debate dos linguistas russos" (BIANCHI, 2017b, p. 28).

2 "essa relação sempre foi muito controversa, porque interpretaram-na de forma idealista. O caso mais notório é o de Bobbio, que desvirtua a concepção dialética" (MARTINS, 2008a, p. 224-225).

${ }^{3}$ Gramsci diz (GRAMSCl, L'Ordine Nuovo - Contra o pessimismo, 15/03/24 - 2004b, p. 242-243): "nós, por uma série de razões, não partimos - para definir nossa ação - daquilo que ocorria na Itália limitamo-nos a insistir em questões formais e fomos derrotados, já que a maioria do proletariado politicamente organizado não nos deu razão, não nos seguiu [...] não soubemos traduzir em linguagem compreensível por todo operário e camponês italiano o significado de cada um dos eventos italianos dos anos 1919-1920".

4 "posição que L'Ordine Nuovo assumiu consistia: 1) Em ter sabido traduzir na linguagem histórica italiana os principais postulados da doutrina e da tática da Internacional Comunista. Nos anos 1919-1920, isso significou a palavra de ordem dos conselhos de fábrica e do controle sobre a produção" (GRAMSCI, L'Ordine Nuovo - O Programa de L'Ordine Nuovo -, 1-15/04/1924 - 2004b, p. 246).

${ }^{5}$ A modificação que Gramsci produziu no conceito de Estado é elucidativa do esforço de tradução. Em 1924, ele tinha a concepção de Estado restrita à sociedade política, como coerção (GRAMSCI, 2005a, p. 235), mudou essa visão no cárcere, ampliando o conceito de Estado, traduzindo-o à realidade das sociedades ocidentais, como "equilíbrio da sociedade política com a sociedade civil" (GRAMSCl, 2005b, p. 84).

6 "a tradutibilidade constitui o núcleo teórico do marxismo gramsciano, que deriva e, ao mesmo tempo, desenvolve algo que em Marx e Lênin era apenas implícito. Além disso, Gramsci se preocupa também em estudar e mostrar como a nova síntese, isto é, a filosofia da práxis, nasceu por meio de uma 'tradução' (interpretada a partir do modo como a entendiam os próprios Marx e Lênin)." (LACORTE, 2014, p. 64)

${ }^{7}$ Escola desinteressada do trabalho de Gramsci "conota horizonte amplo, que interessa objetivamente não apenas a indivíduos ou a grupos, mas à coletividade e até à humanidade inteira" (NOSELLA, 1992, p. 14); "em português, [desinteressado] se contraporia a 'interesseiro, mesquinho, individualista, de curta visão, imediatista e até oportunista'. Nessa direção, ele resgata o sentido de 'cultura desinteressada', como sendo uma cultura de ampla visão, séria, profunda, universal e coletiva, que interessa a todos os homens." (Idem, Ibidem, p. 18)

8 "O conceito e o fato do trabalho é o princípio educativo imanente à escola primária, já que a ordem social e estatal (direitos e deveres) é introduzida na ordem natural pelo trabalho. [Isso] cria os primeiros elementos de
}

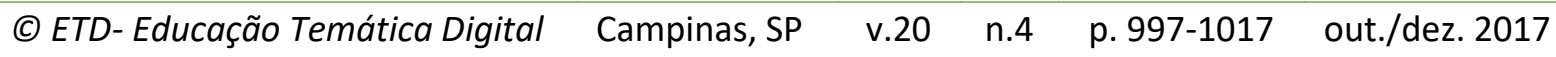


uma intuição do mundo liberta de toda magia ou bruxaria, e fornece o ponto de partida para o posterior desenvolvimento de uma concepção histórica, dialética" (GRAMSCI, Cad. 12, § 2 - 2000a, p. 43).

${ }^{9}$ Até porque "estudo é também um trabalho, e muito cansativo" (GRAMSCI, Cad. 12, § 2 - 2000a, p. 51).

10 Isso significa rompimento com o dualismo escolar ("saber" à burguesia e "fazer" aos trabalhadores), reprodutor da sociabilidade capitalista e presente na escola fascista.

11 "Saviani faz referência a Bourdieu e Passeron quando remete ao conceito de habitus para elaborar o conceito de catarse na PHC, somado a indicação da "articulação com o conceito de 'segunda natureza' de Gramsci"

(CARDOSO; MARTINS, 2014, p. 156).

12 "O homem deve ser concebido como um bloco histórico de elementos puramente subjetivos e individuais e de elementos de massa e objetivos ou materiais, com os quais o indivíduo está em relação ativa. Transformar o mundo exterior significa desenvolver a si mesmo" (GRAMSCI, Cad. 10 - Parte II, § 44 - 1999, p. 406).

13 "A figura de Leonardo torna-se metáfora de um projeto para o futuro, que mantém os pés no presente: 0 homem moderno como uma síntese leonardesca do engenheiro americano, do filósofo alemão e do político francês, da técnica avançada, do jacobinismo revolucionário e do marxismo" (RAGAZZINI, 2005, p. 15).

${ }^{14}$ Sobre a controvérsia relativa à denominação dessa pedagogia, cf. a entrevista de Saviani (SAVIANI, 2015a).

${ }^{15}$ Forte influência teve em Saviani o livro de Snyders (1976), Escola, classe e luta de classes.

${ }^{16}$ Nesse debate, há controvérsias em relação à apropriação de Gramsci na educação. Soares é uma das estudiosas da área que acusa Saviani, entre outros, de equivocadamente ter trazido Gramsci para este campo de maneira não historicista, porque fez uma leitura logicista do sardo, o que segundo ela marcou a sua apropriação no Brasil. Todavia, não parece ser razoável essa crítica (SAVIANI, 2013a, p. 14).

${ }^{17}$ A pergunta foi feita pelo autor deste artigo na palestra de Saviani na FE-Unicamp, dia 21/05/2017, promovida como atividade de encerramento da disciplina "Seminários Avançados I: Gramsci e a Educação", ministrada pelo Prof. Dr. Renê J. T. Silveira. Em breve, a referida palestra será disponibilizada na Internet.

${ }^{18}$ Essa orientação próxima ao "tempo de longa duração" de Braudel, Saviani empregou em História das ideias pedagógicas no Brasil (SAVIANI, 2007b) e em História do tempo e tempo da história (SAVIANI, 2015c).

${ }^{19}$ Bourdieu e Passeron, Althusser e Baudelot e Establet (SAVIANI, 1983, p. 20-34).

20 "uma das grandes fraquezas dos métodos novos. Sem o domínio do conhecido, não é possível incursionar pelo desconhecido. É aí que está também a grande força do ensino tradicional." (SAVIANI, 1983, p. 51)

${ }^{21}$ Para Saviani (1982, p. 20), nem todos os problemas são problemáticos: "qual é, então, a essência do problema? É a necessidade. [...] uma questão, em si, não caracteriza o problema, nem mesmo aquela cuja resposta é desconhecida; mas uma questão cuja resposta se desconhece e se necessita conhecer".

22 "Há os que imaginam que a uma concepção dialética de educação corresponde uma pedagogia dialética e, por conseqüência, uma didática dialética. [...] esperam por uma nova didática construída em seu todo, com regras claras e acabadas, prontas para ser aplicadas pelo professor. Nessa expectativa não se dão conta de que é precisamente a concepção dialética que desautoriza tal entendimento." (SAVIANI, 1989, p. 7)

*Revisão gramatical do texto sob responsabilidade de:

Marcio Antônio Gatti - E-mail: maggatti@gmail.com

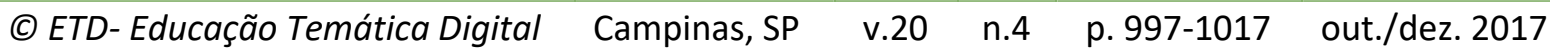

